\title{
Comparison of passive design strategies to improve living conditions: a study in Ondjiva, Southern Angola
}

\author{
Joana Aleixo ${ }^{1,2}$, Gonçalo Roque Araújo ${ }^{1}$, and Manuel Correia Guedes ${ }^{1, *}$ \\ ${ }^{1}$ Instituto Superior Técnico, Lisbon, Portugal \\ 2 École Polytechnique Fédérale de Lausanne, Lausanne, Switzerland
}

Received: 27 March 2021 / Received in final form: 2 June 2021 / Accepted: 2 June 2021

\begin{abstract}
Passive design strategies aim at creating comfortable buildings while reducing their energy consumption. Simple strategies such as the correct orientation of the building, the correct design of the building's openings, or the correct sizing of the building's constituent parts (such as walls, ceilings, etc.) according to their material specificities (regarding the region's climate) would greatly improve the performance of a building. This paper intends to show how the application of simple passive techniques in housing design can reduce the energy loads spent annually and improve the house's interior comfort. It translates the results of interior comfort computer simulations into suggestions for the application of passive strategies in housing design, to improve the living conditions in Southern Angola.
\end{abstract}

\section{Introduction}

"There are many definitions of sustainable architecture, but the essence of sustainability is intrinsically linked to the essence of architecture. A good building is naturally sustainable." [1].

It is essential to understand the surrounding environment and to take advantage of natural resources to improve the architectural project in the question of the building's performance. Simple strategies such as the correct orientation of the building (regarding the sun path), the correct design of the building's openings (regarding natural light and ventilation), or the correct sizing of the building's constituent parts - such as materials for walls, ceilings, among others - would greatly improve the performance of the building [2]. Furthermore, vernacular buildings, born out of traditional customs, can give us some clues about what strategies to apply in specific geographical and climatic settings, by taking advantage of the natural resources available.

This paper intends to show how the application of simple passive techniques in housing design can reduce the energy loads spent annually and improve the house's interior comfort. It translates the results of interior comfort computer simulations into suggestions for the application of passive strategies in housing design, to improve the living conditions in Southern Angola.

\footnotetext{
* e-mail: manuel.guedes@tecnico.ulisboa.pt
}

\subsection{Sustainable and bioclimatic concerns in the improvement of living conditions}

Passive design strategies aim at creating comfortable buildings while reducing their energy consumption. Many world organizations have been making efforts to improve sustainable development, by defining clear-cut construction methods, issuing directives, holding discussions, and taking initiatives to develop sustainable construction; they are, among others, UNEP (United Nations Environment Programme), PLEA (Passive \& Low Energy Architecture), INTA (International Network for Tropical Architecture), GB4all (Green Buildings For All) and UN-Habitat (United Nations Habitat).

There is also a considerable body of literature concerning passive techniques for hot and tropical climates, where suggestions for more integrated and sustainable approaches to construction are given. The most important reference we consider in this respect is Givoni [3], who defined different hygrothermal comfort zones of influence for different passive strategies, according to specific climatic characteristics.

Lauber [4] has produced important work on how traditional and pre-colonial buildings were better adapted than modern ones to the local topography and climate. He explains why this happened and draws attention to the need to adequately adapting the building to its surrounding environment.

Baker [5] carried out important studies on how to reduce building costs by interacting with builders - for example, by designing simple manuals that would guide 

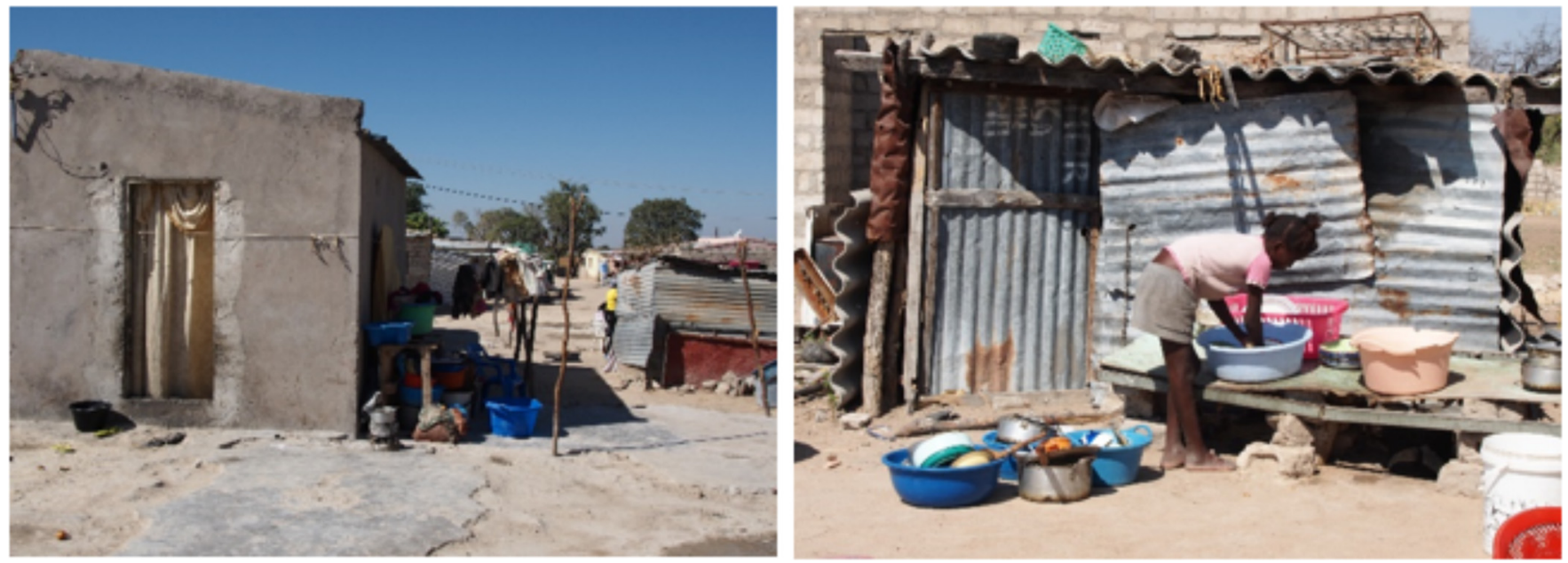

Fig. 1. Examples of poor housing in the city of Ondjiva.

them through the construction of rural houses. These would include "principles of good housing for whatever strata of society in whatever geographic or climatic regions, and concerning planning, design, materials and construction techniques".

Van Dresser [6] wrote an interesting and helpful book about solar housing, which can easily be read and put into practice by lay people (who are not architects or engineers). Lopes [1] and Van Lengen [7] are two excellent examples of authors who designed manuals about good building practices that take into account the type of climate and geomorphology, the prevailing winds, sun path, etc., and suggest specific bioclimatic techniques for each group of environmental constraints - most of the time, these are very easy to apply and will reduce the building cost because they imply using readily available materials, such as wood, sand or stone. Furthermore, these three authors also suggest simple and sustainable ways of saving energy, for example, by storing and using rainwater in the housing infrastructure or by using solar energy without having to invest in solar panels.

These authors are mentioned here mainly because of their will to reach ordinary people as their main target, but also because they focus on self-built housing. Their work provides examples of research and tools that were created considering the improvement of sustainable construction (mainly in the field of housing), intending to show that it is possible to improve housing construction (to make it more comfortable and less expensive) by using the available resources.

If a great percentage of the world's housing (especially in developing countries) is self-built and at the same time lacks the minimum conditions (hygiene, hygrothermal comfort, construction quality), then it is urgent to spread this kind of information through the already existing tools (manuals, workshops, books, articles, etc.) or to keep trying to suggest new ways of making this information reach those who are responsible for construction.

Some of the "key strategies" included in studies developed for tropical climates are "the promotion of ventilation through openings and the prevention from climate agents" [7]. In terms of town planning, regulations concerning regular road planning - requiring the passage of breezes and shade from trees - are considered crucial, not only to prevent buildings from overheating but also to protect roads from the consequences of rainfall $[1,8]$.

In the specific case of Angola, unfortunately, there is still very little work done and most constructions still require more detailed and sustainable design. However, some efforts have been made in the field of sustainable construction that are noteworthy, such as those of national universities, which have encouraged students to take part in conferences, colloquiums, and even competitions on sustainable architecture and engineering [9].

\section{Methodology}

The research methodology involved both a field survey in Ondjiva and software simulations, which will be described below.

\subsection{The case study of Ondjiva}

Ondjiva $\left(17^{\circ} 04^{\prime} 00^{\prime \prime} \mathrm{S}, 15^{\circ} 43^{\prime} 59^{\prime \prime} \mathrm{E}\right)$ - city and commune - is the capital of the province of Cunene, in Angola, and is located in the municipality of Kwanyama. Under the Ph.D. research in which this paper is based, a survey was made in the city including, among complementary interviews to the local inhabitants and multidisciplinary studies about the city, five in-depth analyses to self-built settlements, in which specific details of the different settlements and their milieus were captured using photographs, drawings, schemata, and house plans. In each of the five case studies, the existing buildings were evaluated in terms of their interior comfort and daylighting using ladybug and honeybee tools [10] that integrate both Energyplus ${ }^{\mathrm{i}]}$ and Daysim $^{[i i]}$ in a single simulation workflow. This integrated simulation approach has yielded promising results in the past for similar analyses and assessments [11,12]. 
Table 1. Prevailing winds during the year in Ondjiva [13], Volume I - Biophysics Report).

\begin{tabular}{|c|c|c|c|c|c|c|c|c|c|c|c|c|}
\hline Months & JAN & FEB & MAR & $\mathrm{APR}$ & MAY & JUN & JUL & AUG & SEP & $\mathrm{OCT}$ & NOV & DEC \\
\hline irection & SE;SW & SE;SW & $\mathrm{SE} ; \mathrm{E}$ & $\mathrm{NE} ; \mathrm{E}$ & $\mathrm{NE} ; \mathrm{E}$ & $\mathrm{NE} ; \mathrm{E}$ & $\mathrm{NE} ; \mathrm{E}$ & $\mathrm{E} ; \mathrm{NE}$ & $\mathrm{E} ; \mathrm{SE}$ & $\mathrm{NE} ; \mathrm{SE}$ & SE;SW & SE;SW \\
\hline
\end{tabular}
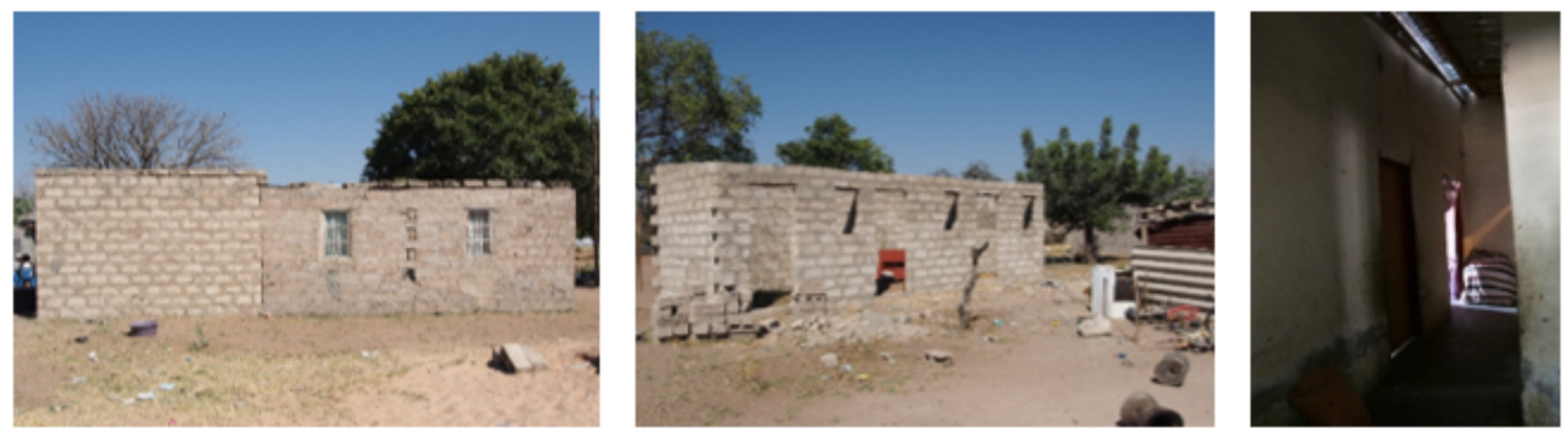

Fig. 2. Example of self-built houses in the city of Ondjiva.

\subsubsection{Main aspects in the establishment of self-built houses} in the city

The buildings where most of Ondjiva's population lives, particularly in suburban areas, are still very poor, with low levels of habitability. Most of the time they respond to an urgent need for shelter, are not built to last, lack basic infrastructure, and do not adequately respond to the harsh weather demands. Thus, such infrastructures are prone to develop unhealthy environments (cf. Fig. 1).

A self-built house usually includes the main building, annexes, and traditional structures. The main building is usually the first to be built, responding initially to an urgent need for shelter; it tends to follow the images and construction standards of consolidated houses in the city and is often built in a phased way, normally starting with just one division, which then develops until it has two-to-three bedrooms, a living room, a kitchen, and a bathroom.

Houses in Ondjiva are generally built with handmade cement bricks used to build the walls, zinc sheets placed over the walls, a combination of stones and cement to build the foundation, and a layer of cement and sand for the floor (placed over the raft foundation) (cf. Fig. 2). There is no reinforcement of the building's structure, no insulation materials are used, and there are no coating materials other than a layer of cement and sand used to protect the building from the external action of natural and climatic erosion.

Cement, zinc sheets, and, sometimes sand are the only materials that inhabitants buy, without including windows and doors (sometimes, in very poor families, these elements only come later in the building process). Most of the time, self-built houses in poor areas do not have enough openings and/or glazed areas, which results in badly lit and badly ventilated spaces. We often find an opening in the wall just waiting for a proper window (one that is not made of cardboard, zinc sheet, or another fragile material), meaning that the inhabitant is just waiting for the money to be able to buy one and install it.

Most of the problems identified by the inhabitants, regarding the lack of comfort inside their house, are related to (1) excessive heat during the day and extreme cold during the night (explained by the high thermal amplitude and by the lack of adequate thermal inertia and insulation), (2) insufficient daylighting inside houses, (3) to the noise that comes in from the exterior, and (4) the lack of water and infrastructure. When houses do not have interior kitchens or bathrooms inside, the activities of cooking, washing dishes, going to the toilet, or taking care of personal hygiene often must be carried out outside. This can lead to the development of unhealthy places, which in turn is responsible for health problems and the rapid spread of diseases.

\subsubsection{Climatic context}

The WMO (World Meteorological Organization) describes Angola's climate as sub-tropical, wet, and dry in most of the territory, semi-arid and arid in the south and along the coastline up until the Province of Luanda. In general, the climate of the Cunene province, where the city of Ondjiva is located, is essential of the semi-arid type, with the rainy season coinciding with the summer months (when the average temperatures are higher).

The local region of Ondjiva has an average annual temperature of around $23^{\circ} \mathrm{C}$, with the highest temperatures occurring during the rainy season and the lowest during the dry season. The coldest months are June and July, with average temperatures close to $17^{\circ} \mathrm{C}$. However, the temperature range between night and day is substantial, reaching 

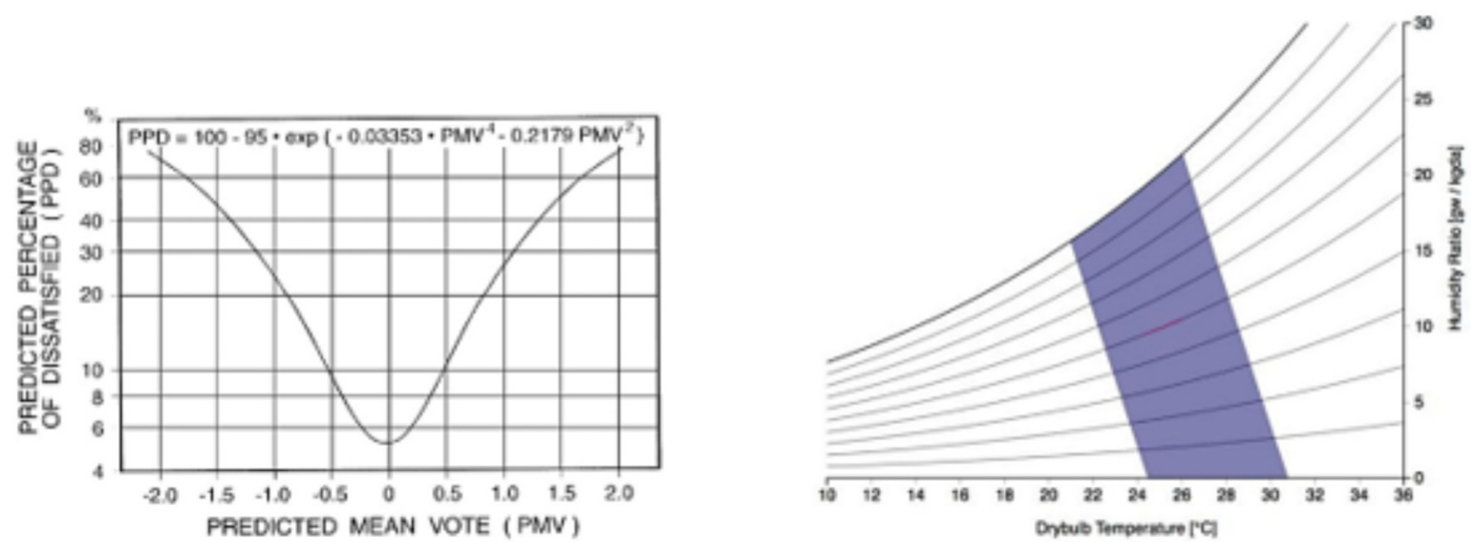

Fig. 3. Predicted-Mean_Vote as a function of the Predicted Percentage Dissatisfied (Left), Psychrometric chart with PMV comfort area. Source: https://support.sefaira.com/hc/article_attachments/115000947631/Screen_Shot_2017-07-07_at_15.32.36.png; https://commons.wikimedia.org/wiki/File:Psychrometric_chart_-_PMV_method.pdf?uselang $=\mathrm{es}$.

very high values - on average, the temperature ranges between night and day in June and July are $19^{\circ} \mathrm{C}$ and $20.6^{\circ} \mathrm{C}$, respectively. The warmer months, October and November, have an average temperature of $26^{\circ} \mathrm{C}$. The absolute minimum temperature recorded for Ondjiva is of $-2.3^{\circ} \mathrm{C}$ in June 1944, whereas the all-time highest temperatures are of $40.5^{\circ} \mathrm{C}$ and $39.9^{\circ} \mathrm{C}$, reached in November 1941 and September 1964, respectively [13].

The extremely high temperatures felt during the day are those that deserve more attention, as well as the hightemperature ranges (close to $20^{\circ} \mathrm{C}$ ). During the day temperatures may reach $30^{\circ} \mathrm{C}$ or more and during the night they may drop to $10^{\circ} \mathrm{C}$ or less, which means that to achieve a good comfort performance inside the house, higher energy consumption would be necessary, unless some bioclimatic strategies would be applied, as demonstrated ahead in point 3 - Computer simulations carried out for the selected buildings.

The average annual rainfall in Ondjiva is about $600 \mathrm{~mm}$; the seasonal cycle of rainfall is associated with a wet season between November and March, flanked by two months of transition, which are October and April. The rest of the year is marked by a dry season [13].

Concerning the wind, on average, the prevailing wind direction in the area of Ondjiva during the year is northeast, followed by strong easterly winds [13] (cf. Tab. 1).

The average annual relative humidity at 9 am in Ondjiva is approximately $47.2 \%$, concerning the observation period $1937-75$. The highest value recorded was for February (68.2\%), whereas the lowest value occurred in September (27\%). The average values of relative humidity are low in areas where daily temperature variations are high [13]. The area of Ondjiva has considerable daily temperature ranges, particularly during the dry season, which means that the water vapor closest to the ground will dissipate during the hottest hours of the day, by convection, into the overlying air layers [13]. Besides having moderate rainfall, Ondjiva's annual evaporation rates are high, which in many cases reduces the availability of surface water. These evaporation rates are influenced by factors such as temperature, solar radiation, humidity, wind speed, atmospheric pressure, as well as the length of the different water surfaces. Evaporation rates in Ondjiva are higher during the summer months preceding the rainy season, due to an increased solar radiation index, higher temperatures, and lower percentages of relative humidity. Evaporation rates are higher in September and October $(463 \mathrm{~mm}$ and $468 \mathrm{~mm}$, respectively), presenting lower values between February and March (178 $\mathrm{mm}$ and $208 \mathrm{~mm}$, respectively) [13]. Thus, the main weather constraints in housing construction in Ondjiva are associated with its high-temperature ranges, high levels of evaporation, and low levels of relative humidity.

\subsubsection{Indoor comfort standards and passive techniques requirements for Ondjiva}

Regarding thermal comfort, there have been many models to assess the comfort of a building's occupant, however, two have risen above others: The Predicted-Mean-Vote (PMV) model, and the Adaptive Comfort model. The PMV model was developed using surveys, in which subjects were asked about their thermal sensation on a scale while standing on a climate-controlled room, correlating their answers with the room's air temperature, mean radiant temperature, relative humidity, airspeed, metabolic rate, and clothing insulation [14]. It quantifies the thermal sensation of the occupant from a value of -3 to 3 , according to the conditions of these six factors. The model is represented as a function of the Predicted Percentage of Dissatisfied people (PPD), and it is calculated through the psychrometric chart, with the comfort area (between -1 and 1 ) being highlighted in the chart (cf. Fig. 3).

Even though the PMV model is applied on a global scale, it does not consider people's adaptation mechanisms and was portrayed as inaccurate in non-conditioned buildings, particularly in hot climates such as in Ondjiva [15]. The adaptive model emerged from surveys within this building type and was based on a direct correlation between the outdoor, and indoor temperatures, and assumes that humans can adapt to different contexts (Dear and Brager 1998). Results were later incorporated in [16] report as the adaptive comfort chart (ANSI/ASHRAE 
Standard 55 2017), which highlights two proportional chart areas in which 80 , and $90 \%$ of the surveyed occupants were comfortable (cf. Fig. 4). Unfortunately, these metrics only describe an occupant's comfort within a point in space and time, failing to represent building performance regarding thermal comfort throughout diurnal, weekly, and seasonal patterns [17].

Thermal autonomy (TA) is introduced both as a metric and a design process, defining it as space's ability to provide acceptable thermal comfort, through passive means only [17]. Specifically, this metric quantifies the percentage of occupied hours during a typical year in which a thermal zone meets or exceeds $80 \%$ of occupant satisfaction in the adaptive thermal comfort chart (cf. Fig. 5). Thus, it provides visual insights regarding diurnal, and seasonal patterns of thermal comfort expected to be delivered by an architectural project.

Passive design strategies allow buildings to adapt to the surrounding environment, through their form and the intelligent use of materials and construction elements, minimizing the dependence on mechanical systems that

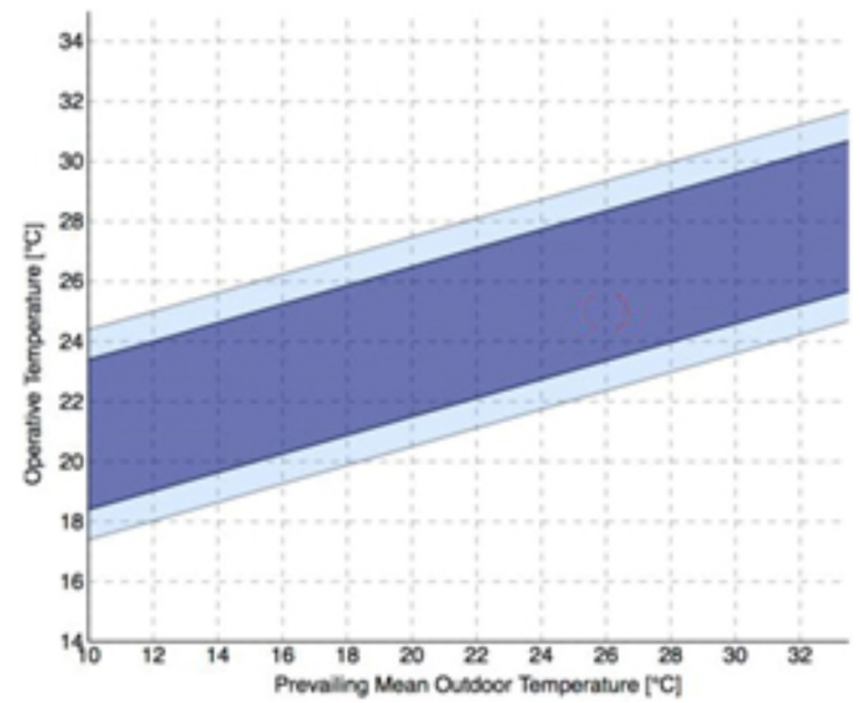

Fig. 4. Adaptive Comfort Chart with comfort areas highlighted for 80 , and $90 \%$ satisfaction. Source: https://commons.wikime dia.org/wiki/File:Adaptive_chart_-_adaptive_method.pdf. consume fossil energy. Additionally, this dependence on fossil energy can also be reduced by improving the use of natural light to reduce the use of artificial lighting systems, or by providing good natural ventilation to avoid the use of air conditioning. Passive cooling techniques aim to prevent overheating and to provide cooling. Despite the existing articles mentioning the great potential benefits of employing passive techniques, their use is still often misunderstood and considered a risk, i.e., possibly inefficient, overly complicated, or expensive [9].

Overheating can occur mainly due to four sources of heat gains: solar gains, internal gains, conduction gains; and ventilation gains (caused by the infiltration of warm air into the building) $[1,3,6,7,9,18,19]$.

Passive techniques for preventing overheating can be divided into two main categories: (1) Techniques for heat protection (that offer thermal protection against the ingress of unwanted heat into the house, minimizing internal gains) and (2) techniques for heat dissipation (that maximize the loss of heat that has accumulated inside the house, dissipating it through natural ventilation, evaporation, radiation or a "hot pit", such as the soil).

\subsubsection{Building performance simulations}

The surveyed houses were simulated for their thermal autonomy [17], Useful Daylight Illuminance (UDI) [20], and operative temperature using ladybug tools [10]. Subsequently, several passive techniques were equally tested as alternatives to the original models, to understand at what point these are capable of modifying and improving the comfort of the building's interior.

The climate data used in the simulations were taken from https://www.ladybug.tools/epwmap/ and it is not exactly in Ondjiva, since there is no data available for the area $\left(17^{\circ} 04^{\prime} 00^{\prime \prime} \mathrm{S}, 15^{\circ} 44^{\prime} 00^{\prime \prime} \mathrm{E}\right)$. Instead, we used the nearest weather data available, which is from Ondangwa in Northern Namibia $\left(17^{\circ} 55^{\prime} 0^{\prime \prime}\right.$ S $15^{\circ} 57^{\prime}$ E).

For each case study and according to their construction-related specificities, the following analyses were made:

Interior and exterior hourly temperatures, for the hottest and the coldest days of the year (Monday 19th November and Sunday 15th July, respectively) in a sample thermal zone of the house;

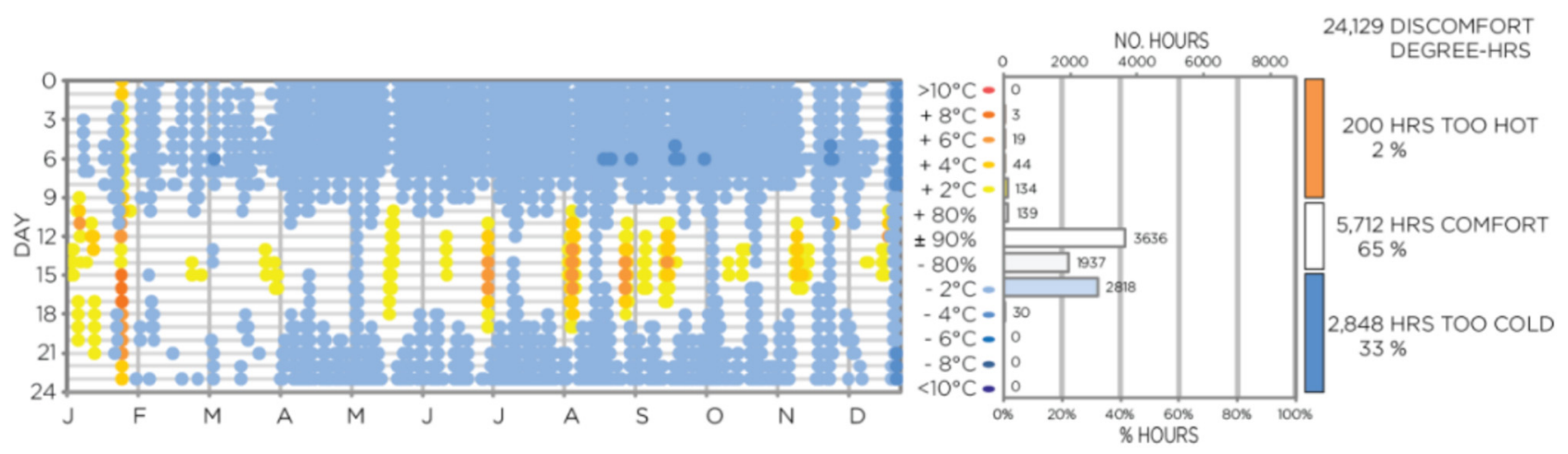

Fig. 5. Annual Temperature heatmap for a thermal zone (left); Thermal autonomy calculation and outliers (right). [17]. 

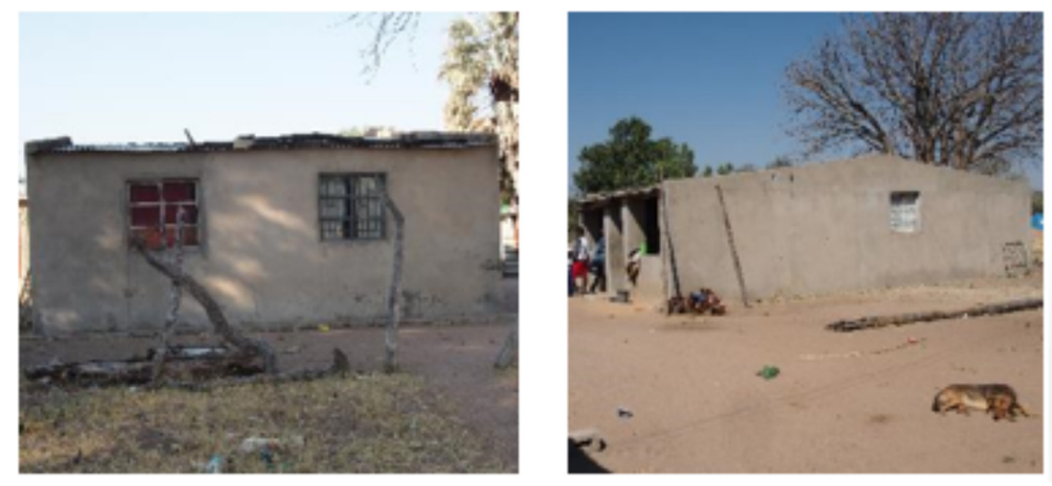

Fig. 6. House in Naipalala, Ondjiva. Composition of the walls: $2 \mathrm{~cm}$ of plaster $+12 \mathrm{~cm}$ of cement bricks $+2 \mathrm{~cm}$ of plaster. Composition of the roof: Corrugated zinc sheets.

Thermal Autonomy, average, and microclimate map, for the hottest and the coldest month of the year (November and July, respectively);

Useful Daylight Illuminance (UDI) - yearly analysis of the percentage of time in which a sensor point is within an acceptable illuminance range (100-2000 lux).

All these analyses were made for the following passive strategies:

- The original model, respecting its construction materials and design;

- A different sizing of the glazing area and added windows to divisions (generally $15 \%$ window to wall ratio). Note: this sizing had in consideration not only the ideal percentage of glazing according to previous studies and analyses made, for example, under the SURE Africa project or for scientific articles [21-24] but also a picture of reality rooted in the poor economic conditions of selfbuilt housing;

- The addition of shading devices in the original model;

- The addition of thermal mass in the walls, in this case by increasing the thickness of the walls; and the addition of insulation in the walls;

- D plus roof insulation. This step intends to show how roofs are the most unprotected surfaces in self-built housing in Ondjiva and how insulating them would significantly improve the building's thermal comfort.

Most of the self-built houses in the city of Ondjiva follow the same kind of construction, are built with the same materials, and tend to follow similar typologies. Therefore, the results from all the analyses did not vary significantly from building to building. Thus, rather than showing an exhaustive list of the results of all the analyses carried out in the research, we will instead focus on one of the studied buildings focusing on the analysis methodology and the implication each passive technique has in the house living conditions.

\section{Results and discussion}

\subsection{House in Naipalala, Ondjiva}

\subsubsection{Original model $(A)$}

The simulation results for the TA and UDI heatmaps respectively show low TA values ranging between $30 \%$ and
$50 \%$ and non-existent illuminance in the two divisions without windows (cf. Fig. 6). These results reflect the surveyed buildings and discomfort felt by the general population in the area.

\subsubsection{Alternative: 15\% Glazing (B)}

Increasing the glazed area to $15 \%$ of each façade (cf. Fig. 7) outputs major improvements in terms of illuminance (cf. Fig. 8). However, by comparing the results with the original model results (cf. Fig. 9), this solution shows an overall similarity in thermal comfort for a warm design day. This means that $15 \%$ of the glazed area, even with natural ventilation schedules is not enough to improve the original house comfort threshold, and smaller glazing ratios should be considered for the housing design and construction. These results illustrate the existing conflicts between thermal and illuminance comfort for passive buildings, where mechanical systems are unavailable [2].

\subsubsection{Alternative: added shading (C)}

In this alternative, horizontal shading devices were included around the original reference house (cf. Fig. 10). Specifically, results showed an overall increase of $11 \%$ in thermal performance and a decrease in illuminance on the divisions with windows when compared with the original (cf. Fig. 11). Results show that these shading devices are not enough to significantly improve an occupant's thermal comfort, and the already poor illuminance performance.

\subsubsection{Alternative: Added Inertia + insulation (air) in the walls (D)}

Composition of the walls: $2 \mathrm{~cm}$ of plaster $+12 \mathrm{~cm}$ of cement bricks $+4 \mathrm{~cm}$ void (air) $+12 \mathrm{~cm}$ of cement bricks $+2 \mathrm{~cm}$ of plaster. Composition of the roof: Corrugated zinc sheets.

In this alternative, inertia and insulation were added to the original model by doubling the wall layer but keeping a gap of $4 \mathrm{~cm}$ in between the two layers. The air in this gap works as insulation. For this solution, the results showed an overall increase of $13 \%$ in all zones compared to the original house, (cf. Fig. 12) which is a similar result to strategy C 

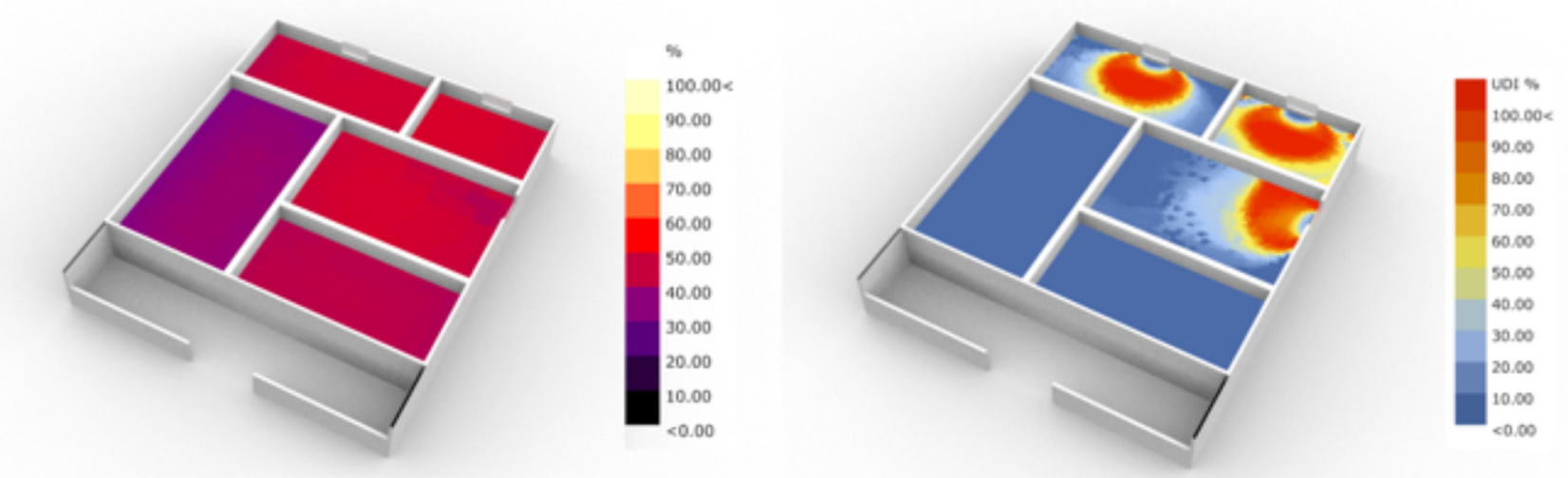

Fig. 7. Simulation results for the common self-built house in Ondjiva (A). Thermal Autonomy microclimate map for a warm design day (left), yearly Useful Daylight Illuminance heatmap (right).

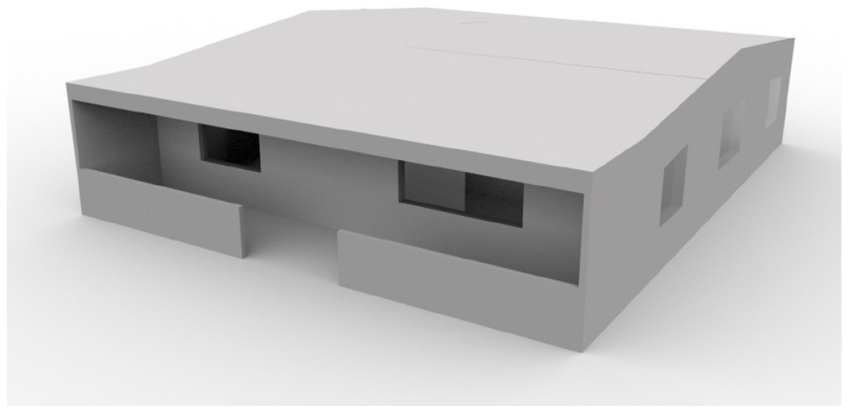

Fig. 8. House in Naipalala, Ondjiva with passive strategy B added to A (Added glazing).
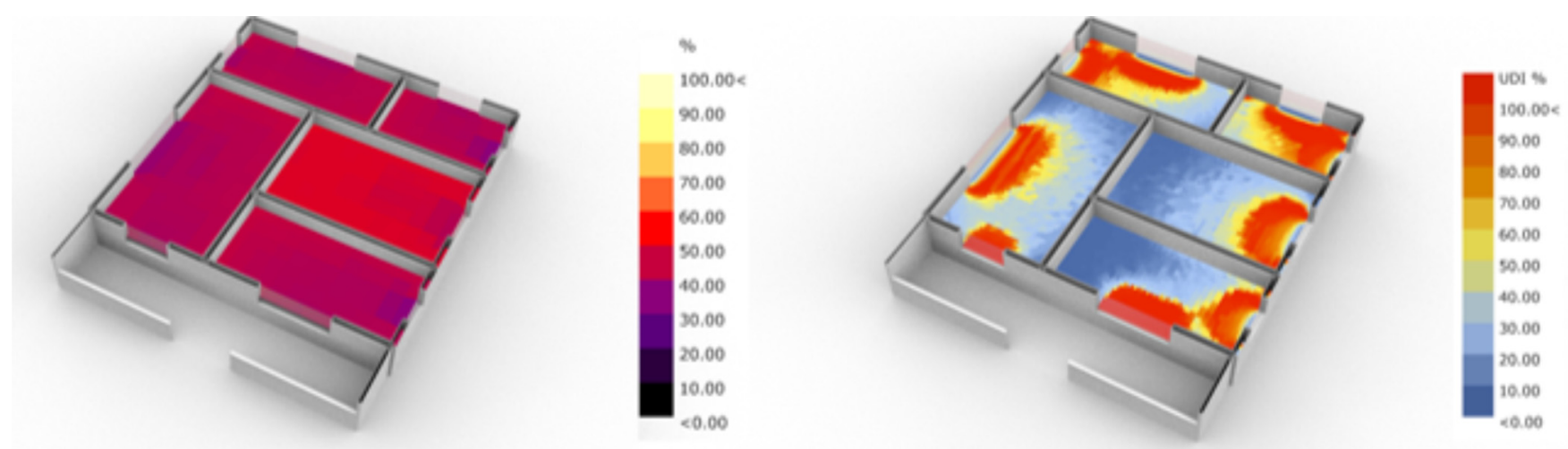

Fig. 9. Simulation results for the common self-built house in Ondjiva with added glazing (B). Thermal Autonomy microclimate map for a warm design day (left), yearly Useful Daylight Illuminance heatmap (right). 


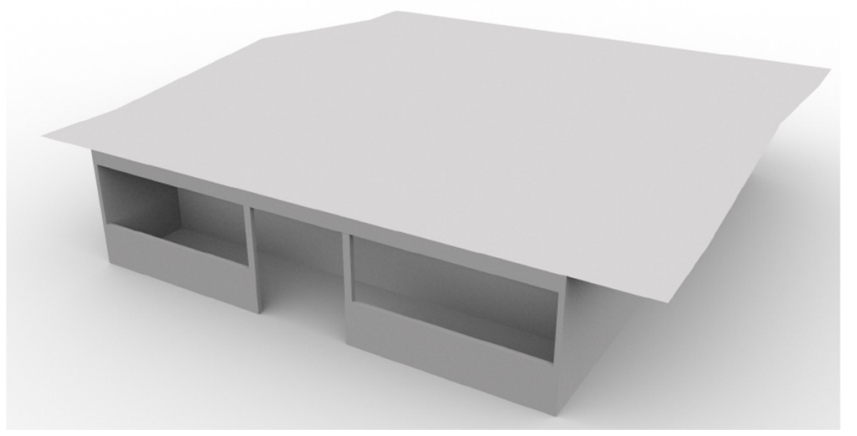

Fig. 10. 3D model of Alternative C: Added Shading.
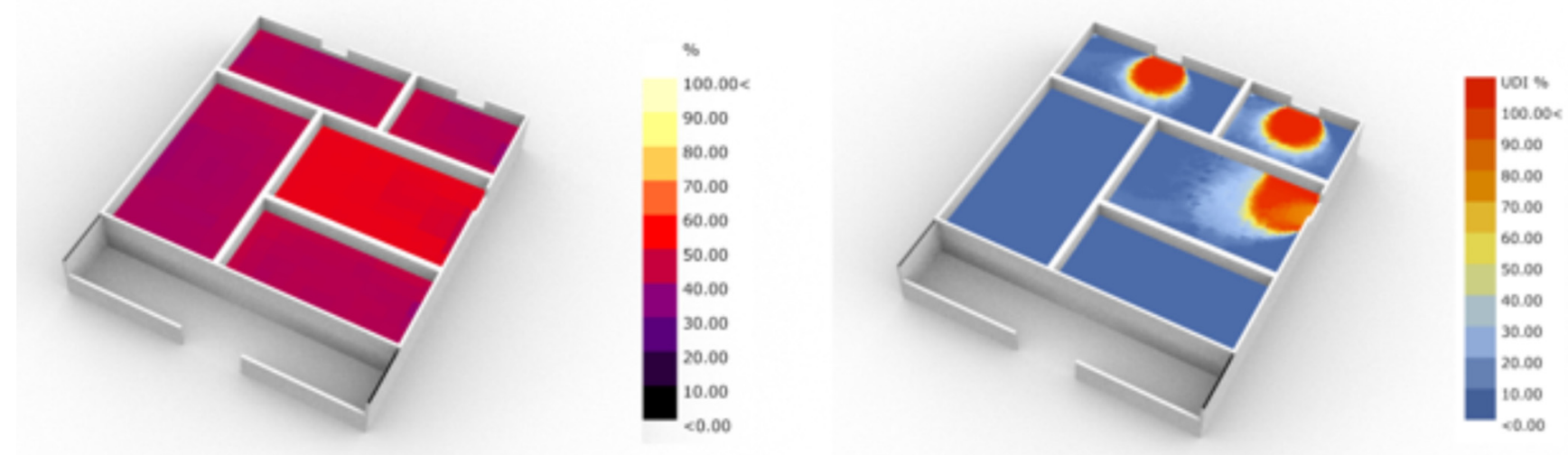

Fig. 11. Simulation results for the common self-built house in Ondjica with added shading devices (C). Thermal Autonomy microclimate map for a warm design day (left), yearly Useful Daylight Illuminance heatmap (right).

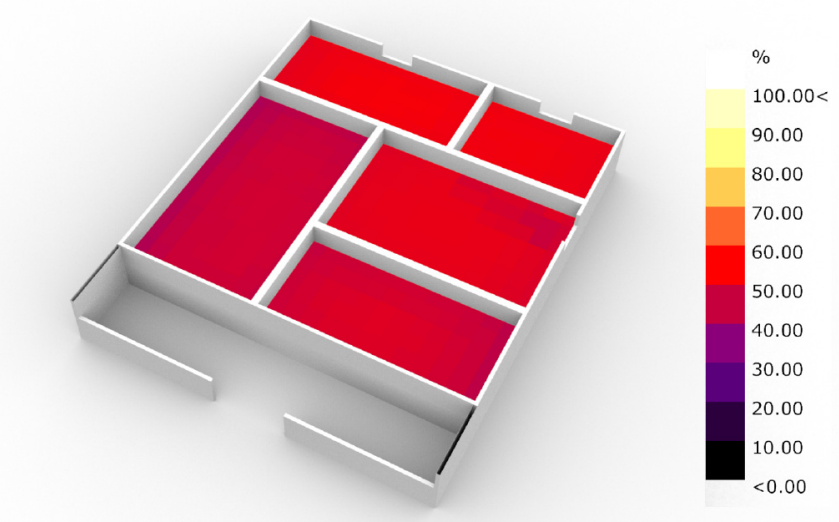

Fig. 12. Simulation results for the common self-built house in Ondjica with added thermal mass (D). Thermal Autonomy microclimate map for a warm design day.

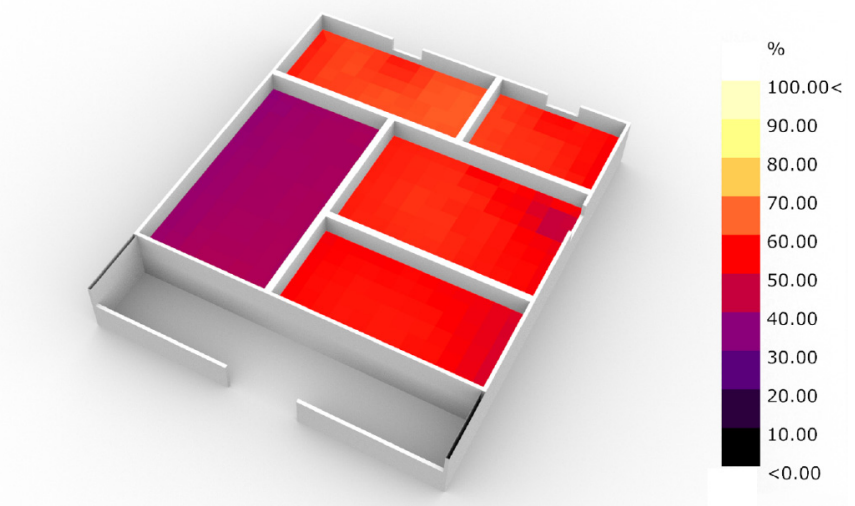

Fig. 13. Simulation results for the common self-built house in Ondjica with added thermal mass to walls and roof insulation (E). Thermal Autonomy microclimate map for a warm design day. 

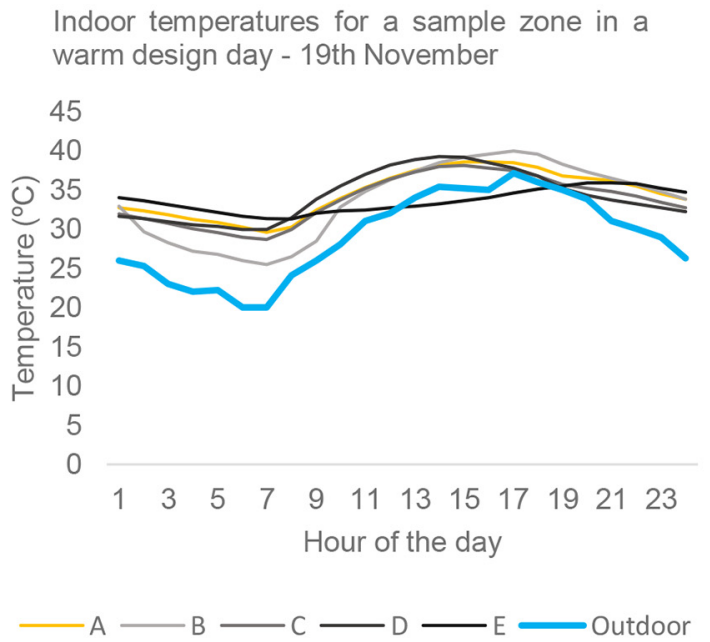

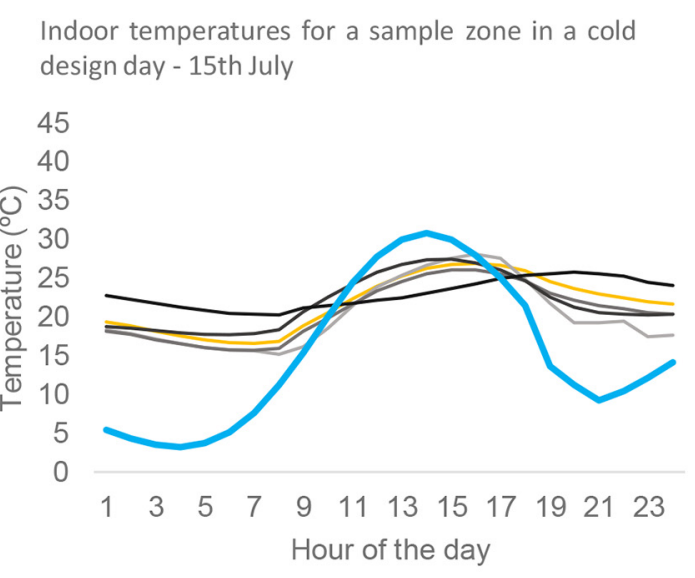

$\longrightarrow \mathrm{A}-\mathrm{B}-\mathrm{C} \longrightarrow \mathrm{D} \longrightarrow \mathrm{E}-$ Outdoor

Fig. 14. Simulation results for the common self-built house in Ondjiva for all the passive strategies and original scenario (A). Indoor temperatures for a sample zone and outdoor temperature for both hot and cold design days.

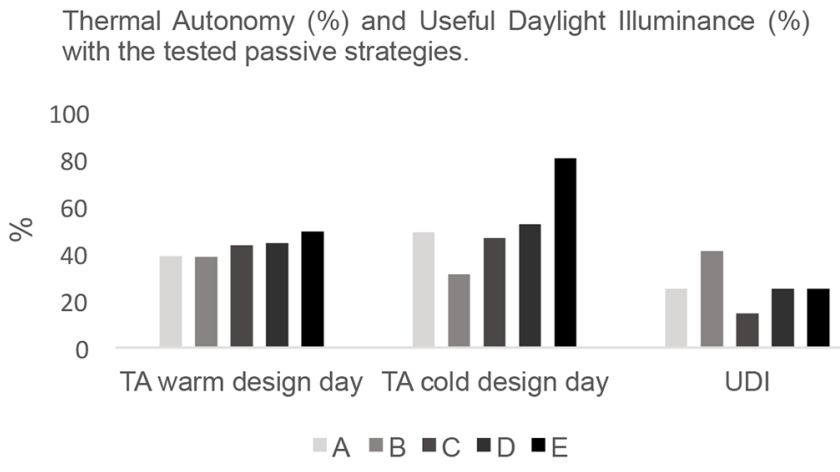

Fig. 15. Simulation results for the common self-built house in Ondjiva for all the passive strategies and original scenario (A). Thermal Autonomy (\%) for a warm and cold design day, and yearly Useful Daylight Illuminance (UDI).

(cf. Fig. 11). However, by looking at the TA microclimate map we see an improvement in most zones. These results show that adding shading devices or increasing the walls' thermal mass provide similar results but take on different costs and convenience, with the former (strategy C) being cheaper and easier to apply.

\subsubsection{D plus roof insulation (E)}

Composition of the walls: $2 \mathrm{~cm}$ of plaster $+12 \mathrm{~cm}$ of cement bricks $+4 \mathrm{~cm}$ void (air) $+12 \mathrm{~cm}$ of cement bricks $+2 \mathrm{~cm}$ of plaster; Composition of the roof: Corrugated zinc sheets $+4 \mathrm{~cm}$ of polyurethane foam for insulation + Corrugated zinc sheets.

In this step, insulation was added to the roof, by including $4 \mathrm{~cm}$ of polyurethane foam between two layers of zinc sheets. For this solution, the results showed a large overall increase of $25 \%$ in the TA when compared with the original scenario A (cf. Fig. 13). These numbers represent a significant improvement in improving the house's thermal comfort. Consequently, it is essential to insulate not only

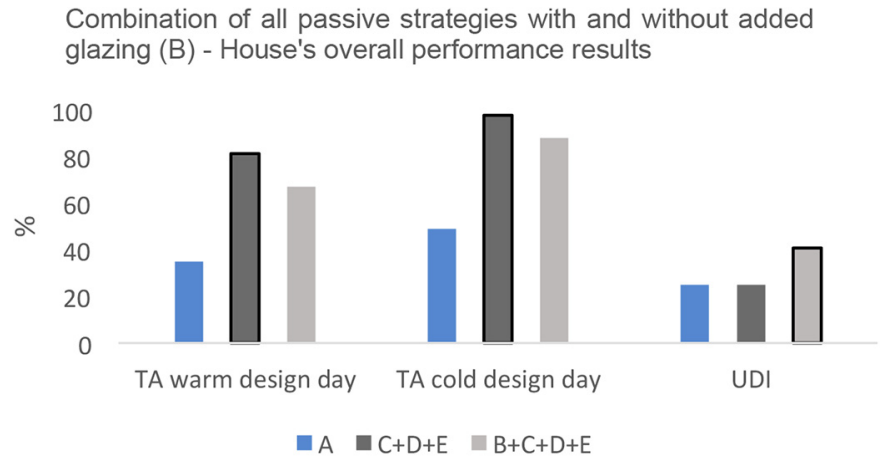

Fig. 16. Simulation results for the common self-built house in Ondjiva for all the passive strategies and original scenario (A). Thermal Autonomy (\%) for a warm and cold design day, and yearly Useful Daylight Illuminance (UDI).

roofs but all the building's surfaces (and to increase the thermal inertia of walls), to improve the performance of the houses in this climatic region.

3.1.6 Comparing original model with alternatives $B, C, D$, E according to Temperatures, Thermal Autonomy (TA), and Useful Daylight Illuminance (UDI)

The results for indoor temperatures in a sample zone for both design days show that the only significant improvements are $\mathrm{D}$ and $\mathrm{E}$, which successfully reduce the thermal amplitude for both design days (cf. Fig. 14). From the graph, it is possible to see a much higher temperature amplitude for cold days, and the impact of insulating the roofs. With strategy $\mathrm{E}$ applied, temperatures range between $30^{\circ} \mathrm{C}$ and $34^{\circ} \mathrm{C}$ for warm days and between $20^{\circ} \mathrm{C}$ and $25^{\circ} \mathrm{C}$ for cold days. Contrastingly, outdoor temperatures for the original scenario (A) range between $30^{\circ} \mathrm{C}$ and $39^{\circ} \mathrm{C}$, and $16^{\circ} \mathrm{C}$ and $28^{\circ} \mathrm{C}$ for both warm and cold design days. 
Looking at the comfort and illuminance performance results (cf. Fig. 15), small differences are seen when compared with the original scenario for the warm design day. However, major improvements are seen in the thermal performance of the cold design day for strategy E, while strategy B successfully increases the house's illuminance performance, but harms the thermal performance. This happens due to the loss of thermal mass on the walls with the increased glazed area and can be dealt with by adding more passive design strategies. This motivates simulations of a house with all the passive strategies. Particularly, if we join all the passive strategies with and without the increased glazing area. Finally, the performance analyses for the different passive strategies highlight the need to study the existing trade-offs between costs and performance improvement of each strategy in each building, particularly when dealing with large rural settlements.

\subsubsection{All passive strategies applied}

All the tested passive design strategies seem to have an incremental effect on the thermal performance of the house when applied together (cf. Fig. 16). When simulating all the strategies with $(\mathrm{B}+\mathrm{C}+\mathrm{D}+\mathrm{E})$ and without the added glazing $(\mathrm{C}+\mathrm{D}+\mathrm{E})$, the abovementioned trade-offs are immediately identified. Results for solution $\mathrm{C}+\mathrm{D}+\mathrm{E}$ show a TA of $80 \%$ for a warm design day and almost $100 \%$ for a cold one, which represents respectively an increase of $132 \%$ and $99 \%$ in thermal performance when compared to the original solution $\mathrm{A}$. However, solution $\mathrm{B}+\mathrm{C}+\mathrm{D}+\mathrm{E}$ not only shows an increase in TA of $92 \%$ and $79 \%$ for a warm and cold design day respectively but also shows an increase of $64 \%$ in the yearly UDI of the house. Solution B $+\mathrm{C}+\mathrm{D}+\mathrm{E}$ can have an even better thermal performance if the added glazing ratio is reduced from $15 \%$ to smaller values or even other designs.

\section{Conclusion}

These simulations, besides aiming to show how buildings behave according to this region's climate, aim to prove that the main thermal inadequacies in self-built housing are related to the lack of insulation on surfaces like walls and roofs, which are more exposed to sun radiation. Moreover, they intend to highlight the importance of insulating roofs, since these are the most directly exposed to the sun, because of their usually "high" path. The analyses also strengthen the idea that thermal inertia and insulation are essential in a climate like the one of Ondjiva in which there is a great temperature range between day and night (around $20^{\circ} \mathrm{C}$ ).

This type of research is essential to contribute towards architectural and building solutions that may mean a step forward in the improvement of living conditions and in the development of building in the future.

However, it must not be forgotten that the standards of comfort used in the simulations consider a maximum temperature of $26.0^{\circ} \mathrm{C}$ for a region where people are used to temperatures around $28-30^{\circ} \mathrm{C}$. The most important is not to create living spaces where people from other regions, accustomed to milder climates, will feel comfortable, but places where people from the climate in question will feel comfortable. This means that following the strategies underlined above in housing construction is a way of fostering the sustainable development of self-built housing in Ondjiva.

This research was funded by the Portuguese national funding agency for science, research, and technology (FCT). The photography work was made by Joana Couto (Architect and Photographer).

\section{References}

1. L. Lopes, Manual Básico de Construção - Guia ilustrado para a construção de habitação. Mindelo, Cabo Verde: Ministério das Infra-estruturas e Habitação, 2001

2. G. Araújo, Software tools, in Bioclimatic Architecture in Warm Climates, edited by M. C. Guedes and G. Cantuaria (eds.) (Springer, Cham, 2019), pp. 229-247

3. B. Givoni, Performance and applicability of passive and low-energy cooling systems, Energy Build 17, 177-199 (1991)

4. W. Lauber, Tropical Architecture: Sustainable and Humane Building in Africa, Latin America and South-East Asia (Prestel Publishing, New York, 2005)

5. L. Baker, Houses, How to reduce building costs, in Centre of Science and Technology for Rural Bruntland report (Our Common Future), 1987 \& United Nations Conference, Stockholm, 1986.

6. P.V. Dresser, Passive Solar House Basics (Ancient City Press, New Mexico, 1996)

7. J. Van Lengen, Manual do Arquitecto Descalço (Livraria do Arquiteto, Rio de Janeiro, 2004)

8. B. Stagno, J. Ugarte, Ciudades Tropicales Sostenibles, Pistas para su Diseño (Instituto de Arquitectura Tropical, San José, Costa Rica: Masterlitho S.A., 2006)

9. M.C. Guedes, Bioclimatic Architecture in Warm Climates: A Guide for Best Practices in Africa (Springer, Cham, Switzerland, 2019)

10. M.S. Roudsari, M. Pak, Ladybug: a parametric environmental plugin for grasshopper to help designers create an environmentally-conscious design, in 13th Conference of International Building Performance Simulation Association, 2013, 3128-3135.

11. G. Araújo, M.C. Guedes, A. Leitão, Integrating algorithmic processes in informal urban and architectural planning: a case study of a Maputo's neighborhood in Proceedings of the 35th Passive and Low Energy Architecture (PLEA) Conference - Planning Post-Carbon Cities, 2020

12. G. Araújo, I. Pereira, A. Leitão, M. Guedes Correia, Conflicts in passive building performance: Retrofit and regulation of informal neighbourhoods, Front. Archi. Res. 2021

13. Governo da Província do Cunene, Plano de Urbanização da Cidade de Ondjiva (Governo da Província do Cunene, Ondjiva, 2005), Volumes I, II and III

14. P.O. Fanger, Thermal Comfort: Analysis and Applications in Environmental Engineering (Mcgraw-Hill, 1970)

15. J.F. Nicol, M.A. Humphreys, Adaptive thermal comfort and sustainable thermal standards for buildings, Energy and Buildings 34, 563-572 (2002)

16. ASHRAE, Standard 55- Thermal environmental conditions for human occupancy (The American Society of Heating, Refrigerating and Air-Conditioning Engineers, Atlanta, GA, 2003) 
17. B. Levitt, M. Ubbelohde, G. Loisos, N. Brown, Thermal autonomy as metric and design process. CaGBC National Conference and Expo: Pushing the Boundary-Net Positive Buildings (2013) 47-58

18. M. Guedes, G. Cantuária, K. Borges, L. Alves, J. Aleixo, I. Pereira, Knowledge Network on Sustainable Architecture: The SURE-Africa Project. Recent Advances in Educational Technologies and Methodologies. In 13th International Conference on Education and Educational Technology. Book of Proceedings, 2014, 83-92

19. M. Guedes, T. Chenvidyakarn, G. Cantuária, K. Borges, L. Alves, J. Aleixo, I. Pereira, The SURE-Africa Project: Sustainable Urban Renewal-Energy Efficient Buildings for Africa, Rev. Lusófona de Arquitectura e Educação 211-218 (2013)

20. A. Nabil, J. Mardaljevic, Useful daylight illuminance: a new paradigm for assessing daylight in buildings, Light. Res. Technol. 37, 41-59 (2005)
21. J. Aleixo, M.C. Guedes, L. Pattaroni, Rethinking the House Form in Poor Areas - Researching a pedagogical methodology to improve self-build housing in Angola by creating a culturally and ecologically sensitive Expert System. Ph.D. Thesis. IST/EPFL, Lisbon and Lausanne, December 2015

22. J. Aleixo, M.C. Guedes, L. Pattaroni, Technical and culturally sensitive solutions to foster sustainable housing in southern Angola, in PLEA 2014, 30th International PLEA Conference, CEPT University, Ahmedabad, December 2014

23. J. Aleixo, M.C. Guedes, I. Pereira, Low Cost Sustainable Building Solutions, Case Studies: Angola and GuineaBissau, in PLEA 2011, 27th International Conference on Passive and Low Energy Architecture, Architecture and Sustainable Development, Book of Proceedings (2011), Vol. 2, 381-387

24. M.C. Guedes, J. Aleixo, Arquitectura Sustentável em Angola: Manual de Boas-Práticas, Edição CPLP, Lisboa (2011) 176

Cite this article as: Joana Aleixo, Gonçalo Roque Araújo, Manuel Correia Guedes, Comparison of passive design strategies to improve living conditions: a study in Ondjiva, Southern Angola, Renew. Energy Environ. Sustain. 6, 21 (2021) 